\title{
A voz que sussurra: fugas e outras formas de agência e resistência dos ingênuos em Palmas/PR
}

\author{
Maria Claudia de Oliveira Martins
}

\author{
Palavras-chave: \\ Tutela \\ Ingênuos \\ Palmas/PR \\ Keywords: \\ Guardianship \\ Ingênuos \\ Palmas/PR
}

\begin{abstract}
Resumo: O presente artigo analisa as fugas e outros modos de ação e resistência evidenciados nos processos de tutela de ingênuos em Palmas, província do Paraná, os quais permitiram entrever tentativas de fazer-se ouvir, de exercer seus direitos de escolha. Um sussurro, diante de tantas vozes e legislações que cercearam a liberdade concedida aos filhos das escravas pela Lei de 1871, mas que ecoa até a atualidade.
\end{abstract}

\begin{abstract}
This article analyzes the leaks and other modes of action and resistance evidenced in cases of guardianship of dupes in Palmas, Paranás province, which allowed a glimpse of attempts to make themselves heard, to exercise their rights to choose. A whisper, in the face of so many voices and laws that curtail the freedom granted to the children of slaves by Law of 1871, but which resonates to the present day.
\end{abstract}

Recebido em 17 de setembro de 2016. Aprovado em 06 de fevereiro de 2017.

\section{Introdução}

Abordar a questão dos ingênuos ${ }^{1}$ é, literalmente, tratar de indivíduos colocados à parte, na sociedade brasileira Oitocentista. Nascidos "em condição livre" ${ }^{2}$, conforme o disposto na Lei ${ }^{3}$, estavam ligados a dois mundos: o dos indivíduos livres e o do cativeiro. E, ao mesmo tempo, não pertenciam efetivamente a nenhum. Não eram escravos, como seus pais (ou mãe, pelo menos); no entanto, a vida deles foi marcada por uma série de amarras legais que os vincularam ao poder senhorial; via de regra, ao do senhor (ou ex-senhor) de sua mãe.

Usando da prerrogativa quea Lein ${ }^{\circ} 2.040$ lhes conferia $^{4}$, a maioria esmagadora dos proprietários de cativos no Brasil optou por permanecer com os menores "beneficiários" da legislação sob seus cuidados e a seu serviço até a maioridade (21 anos), como compensação aos custos havidos com eles no dia a dia (por exemplo: comida, roupa, abrigo). Conforme Papali (2007, p. 152), se, por um lado, a referida legislação confrontou o poder senhorial em alguns de seus dispositivos (como o que permitia aos escravos a constituição de pecúlio para a compra de alforria), por outro foi extremamente conservadora por atrelar ao costume, pautado na Legislação Orfanológica, as condições para a vida dos ingênuos até sua maioridade.

A abolição da escravatura, porém, abrindo espaço à dispersão das escravarias, retirou das mãos daqueles mesmos senhores os ingênuos a seu dispor, o que lhes levou à elaboração de estratégias que renovassem os laços de dependência que aparentemente ${ }^{5}$ se despedaçavam. Um destes estratagemas foi a tutela dos menores filhos de suas ex-escravas.

Processos de tutela de menores em geral, principalmente nas últimas décadas dos Oitocentos, foram bastante corriqueiros e podiam abranger três tipos de tutelados: herdeiros menores de idade, crianças filhas de pais livres e pobres e filhos de excativas. No primeiro caso, tratava-se de preservar os interesses e bens dos órfãos, de modo a lhes garantir o acesso à integralidade de suas heranças, quando de sua maioridade. Nos demais casos, assumiu o

\footnotetext{
* Mestranda em História pela Universidade de Passo Fundo (UPF). Bolsista da Coordenação de Aperfeiçoamento de Pessoal de Nível Superior (CAPES). E-mail: claudia.om@terra.com.br
} 
aspecto de uma estratégia de cooptação de mão de obra de baixo custo por um período prolongado, muito mais do que um ato caritativo para com as crianças (ALLANIZ, 1997, p. 58). Diante da proposta de análise quanto à tutoria de ingênuos, deter-me-ei ao $3^{\circ}$ caso.

O lócus para a pesquisa refere-se ao município de Palmas, no atual Estado do Paraná, que no último quartel do século XIX sediava uma extensa comarca $^{6}$, cuja principal atividade econômica era a pecuária (criatório de gado bovino, cavalos e muares) e o aluguel de campos de pouso para o tropeirismo, nas fazendas locais (SIQUEIRA, 2009, p. 2). Ali, empregou-se a mão de obra cativa, atendendo às especificidades daquela lida, pequenas plantações (para consumo interno) e o trabalho doméstico.

Já as fontes utilizadas referem-se aos processos de tutela sob arquivo na Vara Cível do Fórum Municipal de Palmas, dos quais selecionei os que diziam respeito a 12 crianças, todas elas filhas de libertas, as quais sete foram registradas como ingênuos, no livro próprio para "registro dos filhos da mulher escrava" implantado nas igrejas por determinação da Lei de 1871. Outras cinco crianças não foram registradas conforme a legislação, mas reuniam as condições ${ }^{7}$ para se enquadrar como ingênuos; apenas os senhores de suas mães driblaram as determinações da legislação contando que, em caso de serem descobertas suas omissões, poderiam alegar ignorância, desconhecimento.

O critério para a seleção foi a ocorrência de fugas e outros expedientes usados pelos menores e que resultaram em queixas de seus tutores ao juiz de órfãos. É importante esclarecer que não se trata do total de processos disponíveis para pesquisa e que este estudo não compreende todos os processos em que houve fuga e outros modos de oposição, mas uma quantidade de processos que permitem lançar um primeiro olhar sobre a questão em Palmas, província do Paraná.
Meu propósito foi analisar as fugas e outros modos de ação e resistência de que os menores se utilizaram como forma de tentar ter voz, em uma sociedade regida por adultos, machista e escravocrata.

\section{Processos de tutelas}

Os processos de tutela transcorriam com bastante celeridade, a partir da solicitação do interessado na tutelagem: em geral, um dia apenas. Bastava que o pretendente a tutor fizesse a petição por escrito ao juiz, indicando a criança, o nome da mãe e referisse o motivo pelo qual desejava tomar a si esta tarefa.

A maior parte dos requerentes alegava querer socorrer o menor, oferecendo aquilo que sua mãe "paupérrima" (palavra muito empregada no período e condizente com a condição que afligiu os libertos - livres, mas deixados "sem eira nem beira", pelo governo central) não podia lhe dar. Outros alegavam muito estimar a criança com quem conviviam em suas fazendas durante o período da escravidão, a ponto de não aceitarem que ela partisse. Havia também os que simplesmente afirmavam querer tomar para si o papel de educar para o trabalho e para a vida, sem muito explicar o que isso significava.

O fato é que as solicitações eram atendidas em breves tempos, com o juiz mandando notificar a mãe do menor a entregá-lo ao seu novo tutor, logo após lavrado o Termo de tutela. O compromisso do tutor, dali em diante seria, quando chamado pelo juiz, comparecer e prestar contas, bem como depositar um pequeno valor anual como soldada para seu tutelado. Em geral, a partir de 14 anos do tutelado e cujo montante este poderia sacar quando chegasse à maioridade (21 anos).

Foram analisados os seguintes processos: 
Tabela 1 - Informações dos tutelados e tutores

\begin{tabular}{|c|c|c|c|c|}
\hline Tutelados & Nome da mãe & Tutores & $\begin{array}{l}\text { Data do } \\
\text { pedido de } \\
\text { tutela }\end{array}$ & Soldada \\
\hline $\begin{array}{l}\text { Antonio } \\
\text { (não chegou a } \\
\text { ser registrado } \\
\text { como ingênuo) }\end{array}$ & $\begin{array}{l}\text { Isabel } \\
\text { (liberta) }\end{array}$ & $\begin{array}{l}\text { Antonio Ferreira Araujo } \\
\text { Proprietário? } \\
\text { (X) SIM ( ) NÃO }\end{array}$ & $22 / 02 / 1889$ & $\begin{array}{l}6 \text { mil réis mensais, } \\
\text { a partir dos } 14 \text { anos } \\
\text { até os } 21 \text { anos. }\end{array}$ \\
\hline $\begin{array}{l}\text { Manoel } \\
\text { (ingênuo) }\end{array}$ & $\begin{array}{l}\text { Estelina } \\
\text { (liberta) }\end{array}$ & $\begin{array}{c}\text { Domingos Ferreira dos Santos } \\
\text { Proprietário? } \\
\text { (X) SIM ( ) NÃO }\end{array}$ & $22 / 04 / 1889$ & 5 mil réis mensais \\
\hline $\begin{array}{l}\text { Henrique } \\
\text { (ingênuo) }\end{array}$ & $\begin{array}{c}\text { Eva Ferreira } \\
\text { (liberta), também } \\
\text { chamada de Eva } \\
\text { Maria da } \\
\text { conceição }\end{array}$ & $\begin{array}{c}\text { Major João Ferreira de Araujo } \\
\text { Proprietário? } \\
\text { ( x) SIM ( ) NÃO } \\
\text { Após sua morte (1897), sua esposa. } \\
\text { Também Francisco Ferreira Bello. }\end{array}$ & $26 / 12 / 1888$ & $\begin{array}{c}5 \text { mil réis, mensais, } \\
\text { cada } \\
\text { Passa para } 50 \text { mil } \\
\text { réis anuais quando } \\
\text { assume a tutela, } \\
\text { Francisco Ferreira } \\
\text { Bello. }\end{array}$ \\
\hline $\begin{array}{l}\text { Benedicto } \\
\text { (ingênuo) }\end{array}$ & $\begin{array}{l}\text { Fermina (ex- es- } \\
\text { crava, liberta) }\end{array}$ & $\begin{array}{c}\text { David José de Moura } \\
\text { Proprietário? } \\
\text { ( ) SIM (X) NÃO }\end{array}$ & $12 / 04 / 1881$ & $\begin{array}{l}\text { Não consta no termo } \\
\text { de tutela. }\end{array}$ \\
\hline $\begin{array}{l}\text { Athanagildo } \\
\text { (ingênuo) }\end{array}$ & $\begin{array}{l}\text { Mariana (Dias) } \\
\text { (ex-escrava) e pai } \\
\text { incógnito }\end{array}$ & $\begin{array}{c}\text { José Maciel de Souza } \\
\text { Proprietário? } \\
\text { ( ) SIM (X) NÃO }\end{array}$ & $28 / 08 / 1888$ & $\begin{array}{l}5 \text { mil réis mensais, } \\
\text { dos } 14 \text { aos } 21 \text { anos }\end{array}$ \\
\hline $\begin{array}{l}\text { Paulo } \\
\text { (ingênuo) }\end{array}$ & $\begin{array}{c}\text { Joana (Maria } \\
\text { Baptista) } \\
\text { (liberta) }\end{array}$ & $\begin{array}{c}\text { Domingos Ferreira de Araujo } \\
\text { Proprietário? } \\
\text { (X) SIM ( ) NÃO }\end{array}$ & $24 / 12 / 1888$ & $\begin{array}{l}4 \text { mil réis mensais, } \\
\text { dos } 14 \text { aos } 21 \text { anos }\end{array}$ \\
\hline $\begin{array}{l}\text { João } \\
\text { (não consta no } \\
\text { registro de ingê- } \\
\text { nuos) }\end{array}$ & $\begin{array}{l}\text { Thereza } \\
\text { (liberta) }\end{array}$ & $\begin{array}{c}\text { Eugenia Ferreira de Siqueira } \\
\text { Proprietário: } \\
\text { (X) SIM ( ) NÃO }\end{array}$ & $29 / 12 / 1888$ & $\begin{array}{l}5 \text { mil réis mensais } \\
\text { para cada, dos } 14 \\
\text { anos } 21 \text { anos }\end{array}$ \\
\hline $\begin{array}{l}\text { Luiza } \\
\text { (não consta no } \\
\text { registro de ingê- } \\
\text { nuos) }\end{array}$ & $\begin{array}{c}\text { Thereza } \\
\text { (ex-escrava de } \\
\text { Eugenia Ferreira } \\
\text { de Siqueira) }\end{array}$ & $\begin{array}{c}\text { Jesuino de Siqueira Cortes } \\
\text { Proprietário? } \\
\text { (X)SIM ( ) NÃO }\end{array}$ & $10 / 09 / 1888$ & $\begin{array}{l}\text { Após os } 12 \text { anos, } 36 \\
\text { mil réis anuais }\end{array}$ \\
\hline $\begin{array}{l}\text { Salomão } \\
\text { (ingênuo) }\end{array}$ & $\begin{array}{r}\text { Estelina } \\
\text { (liberta) }\end{array}$ & $\begin{array}{c}\text { Estevão Ribeiro do Nascimento } \\
\text { Proprietário? } \\
\text { ( X ) SIM ( ) NÃO }\end{array}$ & $26 / 10 / 1888$ & 6 mil réis mensais \\
\hline $\begin{array}{c}\text { Alipio } \\
\text { (ingênuo) }\end{array}$ & $\begin{array}{c}\text { Maria } \\
\text { (ex-escrava) }\end{array}$ & $\begin{array}{c}\text { Antonio Diniz de Freitas } \\
\text { Proprietário? } \\
\text { (X) SIM ( ) NÃO }\end{array}$ & $17 / 12 / 1888$ & 5 mil réis mensais \\
\hline $\begin{array}{c}\text { Felisbino } \\
\text { (não consta } \\
\text { nos registros de } \\
\text { ingênuos) }\end{array}$ & $\begin{array}{l}\text { Maria Marques } \\
\quad \text { (liberta) }\end{array}$ & $\begin{array}{c}\left(\mathrm{X}^{*}\right) \mathrm{SIM}(\mathrm{)}) \mathrm{NÃO} \\
{ }^{\star} \text { Filho do ex-proprietário }\end{array}$ & 09/08/1888 & $\begin{array}{l}20 \text { mil anuais dos } 12 \\
\text { aos } 14 \text { anos e } 40 \text { mil } \\
\text { réis anuais dos } 14 \\
\text { aos } 21 \text { anos }\end{array}$ \\
\hline $\begin{array}{c}\text { Ricardo } \\
\text { (não consta } \\
\text { nos registros de } \\
\text { ingênuos) }\end{array}$ & $\begin{array}{l}\text { Ephigênia Maria } \\
\text { (liberta) }\end{array}$ & $\begin{array}{l}\text { Cândido Cerostre de Oliveira } \\
\text { Proprietário? } \\
\text { ( ) SIM ( X ) NÃO }\end{array}$ & $26 / 06 / 1888$ & Não consta \\
\hline
\end{tabular}

Fonte: Fórum Municipal de Palmas/PR - Vara Cível. Processos de tutela. 
Um dado que imediatamente se destaca na Tabela 1, já em um primeiro olhar, é a opção nada casual por solicitação da tutela de meninos. $O$ fato de constar apenas uma menina nos processos listados e as demais crianças serem todas do sexo masculino não é um caso à parte e a explicação, para Palmas, parece residir na especificidade do trabalho na região, voltado à pecuária. Segundo Monsma (2011, p. 1), por ser um trabalho que, por vezes, exigia força e no qual algumas tarefas eram efetuadas com maior eficácia e destreza quando treinadas desde a infância, então faria sentido uma procura quase unânime por meninos. No entanto, essa mesma prevalência ocorre em outras partes do Brasil, em atividades diversificadas. Raquel Francisco (2007, p. 656) explica que "[...] as abordagens sobre tutela de menores desvalidos têm demonstrado que o sexo masculino se fez mais presente nestes processos", além de citar as pesquisas de Alessandra David (1997) - Franca/SP - e de Arethuza Zero (2004) Rio Claro/SP - como aquelas que encontraram essa mesma evidência.

Dos dados apresentados, a prevalência dos ex-proprietários das escravas ou membros diretos das famílias dos senhores, podemos afirmar, "grita". Em 12 processos, nove deles enquadramse nesta condição, reforçando a ideia de tentativa de manutenção do controle sobre a nova situação econômica e social que emerge no Brasil pósabolição. Manter os filhos consigo poderia ser uma forma de fazer com que a família permanecesse próxima, por exemplo. Precisando dos meios para sobreviver e desejando estar próximos ao menor, caberia aos ex-senhores de escravos, mais uma vez, determinar as condições de vida e trabalho.

É igualmente significativo perceber que 11 dos 12 processos têm seu início no período de até 11 meses após da extinção da escravidão no Brasil e apenas um único processo foi aberto em 1881. Também, que nove de 11 processos referemse especificamente ao ano de 1888 . De tais dados, podemos depreender que a abolição, ao mesmo tempo em que libertou os antigos escravizados, colocou por terra conjuntamente os dispositivos que regiam a Lei do Ventre Livre. Acabara o domínio sobre os pais e de quebra, terminara o uso dos serviços dos ingênuos, ditos menores "livres"!
Assim, restou aos escravocratas mais uma vez procurar meios de continuar usufruindo, nem que fosse de forma adaptada, do trabalho alheio. $\mathrm{E}$ gratuito. Mas isso precisava ser resolvido rápido. Não afirmo, com isso, que não possa ter havido tutorias realizadas em nome de bons propósitos e sem exploração dos menores, mas o desfecho das tutelagens que destaco nesta pesquisa entendo ser representativo de que parecem ter prevalecido os propósitos que defendo em minha linha de argumentação (tutela como estratagema de vinculação e exploração).

De todas as crianças as quais foram deferidas suas tutelas, nos processos apresentados na Tabela 1, apenas uma das mães foi consultada a respeito. Isso porque o pretendente a tutor afirmou que ela concordava em ceder seu filho para a tutoração, o que se revelou verdadeiro. As demais, em nenhum momento foram ouvidas, sequer perguntadas se anuíam com o processo. Em relação às crianças, menos ainda foram ouvidas. Mesmo por que em pleno século XIX a infância ${ }^{8}$ não tinha as características atuais, nem a liberdade de argumentar e questionar, características habituais da atualidade. Se fossem crianças negras ou mestiças, então... Ao filho livre da mulher cativa cabia buscar outras formas de se fazer ouvir.

\section{Tutelados, mas não submissos}

E eles tentaram.

Recorreram ora ao não trabalho, ora às fugas, ora ao descompromisso com o que se esperava deles como forma de resistência, de marcar sua posição diante de um direcionamento dado por terceiros às suas vidas. Procuraram quem lhes oferecesse guarida, pessoas que eles mesmos houvessem escolhido. Acima de tudo, escolheram a mais das vezes, retornar para sua família ${ }^{9}$.

Por meio da tabela a seguir, pode-se conhecer um pouco mais dos "fujões" deste estudo, mas que também podem ser descritos como agentes do próprio caminho, resistentes às imposições dos membros livres e brancos da sociedade. Afinal, não eram também eles, livres? Quais os limites dessa liberdade? Ou melhor, onde estava o limite para as restrições às suas liberdades? 
Tabela 2 - Fugas e resistências

\begin{tabular}{|c|c|c|c|c|c|}
\hline Tutelados & $\begin{array}{l}\text { Idade na } \\
\text { concessão } \\
\text { da tutela }\end{array}$ & $\begin{array}{c}\text { Idade no } \\
\text { período da fuga }\end{array}$ & Tutores & $\begin{array}{l}\text { Data do pedido } \\
\text { da tutela }\end{array}$ & Fuga \\
\hline Antonio & $\begin{array}{c}1 \text { ano e meio de } \\
\text { idade }\end{array}$ & 19 anos & $\begin{array}{c}\text { Antonio Ferreira } \\
\text { Araujo }\end{array}$ & $22 / 02 / 1889$ & $\begin{array}{c}\text { Comunicada em } \\
20 / 02 / 1906\end{array}$ \\
\hline Manoel & 7 anos & 17 anos & $\begin{array}{c}\text { Domingos Ferreira dos } \\
\text { Santos }\end{array}$ & $22 / 04 / 1889$ & 1899 \\
\hline Henrique & 5 anos & 17 anos & $\begin{array}{l}\text { Major João Ferreira de } \\
\text { Araujo. E, em razão de } \\
\text { sua morte, sua esposa. } \\
\text { Francisco Ferreira } \\
\text { Bello. }\end{array}$ & $26 / 12 / 1888$ & 1900 \\
\hline Benedicto & 5 anos & 15 anos & David José de Moura & $12 / 04 / 1881$ & 1891 \\
\hline Athanagildo & 1 ano e meio & 17 anos & $\begin{array}{l}\text { José Maciel de Souza } \\
\text { Manoel Ignácio de } \\
\text { Araujo Pimpão }\end{array}$ & $\begin{array}{c}28 / 08 / 1888,1^{\circ} \text { tutor; } \\
26 / 12 / 1904 \\
2^{\circ} \text { tutor; }\end{array}$ & 1904 \\
\hline Paulo & 2 anos & 20 anos & $\begin{array}{c}\text { Domingos Ferreira de } \\
\text { Araujo }\end{array}$ & $24 / 12 / 1888$ & $14 / 02 / 1906$ \\
\hline João & 12 anos & 15 anos & $\begin{array}{c}\text { Eugenia Ferreira de } \\
\text { Siqueira }\end{array}$ & $29 / 12 / 1888$ & 02/01/1892 \\
\hline Luiza & 8 anos & 12 anos & $\begin{array}{c}\text { Jesuino de Siqueira } \\
\text { Cortes }\end{array}$ & $10 / 09 / 1888$ & 1892 \\
\hline Salomão & 3 anos & 20 anos & $\begin{array}{l}\text { Manoel Ignácio de } \\
\text { Araujo Pimpão }\end{array}$ & 04/06/1881 & Janeiro de 1898 \\
\hline Alipio & 3 anos & $\begin{array}{c}\text { Dos } 15 \text { até os } 21 \\
\text { anos }\end{array}$ & $\begin{array}{l}\text { Antonio Diniz de } \\
\text { Freitas. E, após sua } \\
\text { morte, em 1898, } \\
\text { Severina Porcina de } \\
\text { Oliveira (esposa). } \\
\text { Após desistência desta, } \\
\text { Moyzes de Ramos An- } \\
\text { drade, em 31/03/1902 } \\
\text { até 1904. }\end{array}$ & $17 / 12 / 1888$ & 1898 em diante \\
\hline Felisbino & 12 anos & 16 anos & Pedro Ferreira Bello & $09 / 08 / 1888$ & Janeiro de 1894 \\
\hline Ricardo & 12 anos & $12 / 13$ anos & $\begin{array}{c}\text { Cândido Cerostre de } \\
\text { Oliveira }\end{array}$ & $26 / 06 / 1888$ & Abril de 1889 \\
\hline
\end{tabular}

Fonte: Fórum Municipal de Palmas/PR - Vara Cível. Processos de tutela.

$\mathrm{Na}$ análise da Tabela 2, um dado passível de ser colocado em evidência é a idade dos menores por ocasião da concessão da tutela, comparado com a idade em que realizam as fugas. Considerando que $58 \%$ haviam sido tutelados entre zero e cinco anos, $17 \%$ entre os seis e dez anos e $25 \%$ na faixa entre $11 \mathrm{e}$ 15 anos, para todos parece haver um marco em que a fuga torna-se a possibilidade de mostrar resistência mais candente: a adolescência. Antes deste período, as reações de aparente desagrado, inconformidade por estar onde e com quem estavam revelam-se de modo mais sutil, transparecendo na desobediência ou na impertinência quanto aos estudos e a tarefas delegadas. O processo do menor Alipio, tutelado aos três anos de idade, revela queixas em relação ao que seus tutores (o ex-proprietário de sua mãe e, em seu falecimento, sua esposa), e estes definem o ingênuo como tendo um mau comportamento ainda na infância. Seu modo de agir reiteradamente contrário às ordens recebidas faz com que se lhe atribua não ser uma criança normal, o que na atualidade não temos como comprovar. De seu processo, extraímos a seguinte frase, registrada no depoimento de sua tutora: "[...] jamais prestou o menor serviço em sua casa pela razão de não ter bom raciocínio e, por este motivo, nada querer fazer". Sobre ele também se 
afirma que, quando era adolescente, fugia para os campos e que precisavam mandar procurá-lo. Agia como alguém alienado à sua realidade? Talvez. Mas seu comportamento também poderia expressar apenas descontentamento, desejo de não viver o que vivia. E as palavras de sua tutora poderiam ser apenas uma forma de denegrir ou de não mostrar perda do controle da situação.

$\mathrm{Na}$ adolescência, em que as tarefas tornavam-se mais complexas, mais próximas do mundo dos adultos e, portanto, mais duras, em que a rede de contatos já havia se ampliado mais do que na infância e o próprio menor compreendia melhor a sua realidade, parecia encontrar em si mesmo ousadia para tentar a fuga como forma de modificar o que estava posto. Sendo o tutor aquele que causou o distanciamento do tutelado em relação à família e tendo lhe imposto um modo de viver distante de sua declarada condição de liberdade, fugir dele e de sua casa torna-se a solução para tentar sanar a problemática. No idealismo da adolescência/ juventude, o fugitivo não considerava que, depois da fuga, viria a perseguição e a obrigatoriedade do retorno, pelo menos enquanto o tutor não desistisse de seu posto.

Em cada um dos processos listados na Tabela 2, foram levadas ao conhecimento do Juiz de Órfãos ${ }^{10}$ as fugas ocorridas. Não exatamente no momento em que ocorria cada uma delas, mas quando começam a acontecer com frequência, se a ausência era prolongada ou quando o tutor queria pedir sua dispensa da responsabilidade assumida. Nos dois primeiros casos, havia a preocupação em ser denunciado e ter de se justificar perante o juiz. Nas tutelas de Alipio, Henrique e Athanagildo, houve desistência e substituição dos tutores, assumindo "cidadãos" indicados pelo magistrado.

Há que se destacar que o motivo das fugas jamais foi perguntado diretamente ao tutelado e que a versão indicada nos documentos era a do tutor. Por outro lado, por mais que o móvel para tal ato não possa ser confirmado, se forem consideradas verídicas as alegações apresentadas pelos tutores que constam no gráfico; então, pode-se inferir que para os menores cujos processos foram analisados neste estudo, o distanciamento da família não teve o peso imaginado (uma vez que foi o motivo para a evasão de apenas dois deles).

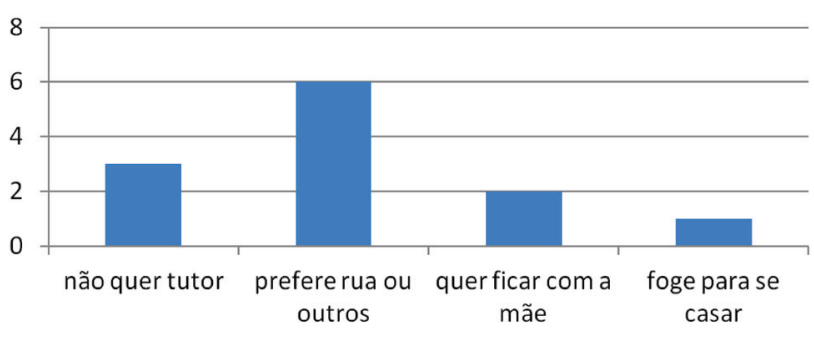

Gráfico 1 - Alegação dos tutores para as fugas Fonte: Processos de tutela. Fórum Municipal de Palmas/PR - Vara Cível.

Ainda sim, o desejo de afastar-se daquele que deveria ser o protetor, o provedor das necessidades básicas dos tutelados (segundo o Termo de tutela) parece demonstrar que a realidade distanciava-se daquela colocada no papel. Se os menores preferiam circular nas ruas ou em companhia de terceiros ou simplesmente repeliam seus tuteladores, o que tal gesto reforça é a ideia de conflitos e de tensões no âmago dessas relações.

\section{Considerações finais}

As recorrentes tutelas de ingênuos, especialmente no período imediato após a emancipação, reforçam a ideia de que escravistas utilizaram-se de todos os expedientes possíveis para manter controle e dominação, quer sobre seus exescravos adultos, quer sobre os filhos daqueles. No caso das tutelas, manter as crianças consigo a seu serviço garantira, por vias indiretas, a não dispersão de seus pais. Em relação aos menores, a tutoria assegurava anos de exercício de sua autoridade e da utilização dos serviços dos infantes.

Atendidas, em geral, de forma célere e sem obstáculos por parte dos magistrados, em muitos casos (como os apresentados neste estudo) as tutelagens foram cotidianamente pautadas por relações marcadas pelos conflitos abertos ou velados, em que as evasões e outras formas 
de resistência foram uma marca. Constituíramse como uma forma de se fazer ouvir, de marcar posição e reivindicar direito de escolha, mesmo que a mais das vezes o "grito" de protesto tenha virado sussurro, diante da imposição de ter de retornar ou continuar sendo tutelado.

\section{Notas}

1 Ingênuo: termo extraído do Direito Romano que definia nascidos livres, com pais livres ou libertos e que tinham direito à plena cidadania.

2 Tal expressão contida na lei (Artigo $1^{\circ}$ ) já denota uma diferenciação entre eles e aqueles simplesmente nascidos brancos livres.

3 Lei $\mathrm{n}^{\circ} 2.040$, de 28 de setembro de 1871, conhecida como Lei do Ventre Livre. (BRASIL, 1871).

4 Parágrafo $1^{\circ}$, artigo $1^{\circ}$ de Lei $n^{\circ} 2.040$. Dispunha que ao senhor era dado permanecer com a criança até seus oito anos de idade, quando então poderia entregá-la ao Estado em troca de uma indenização ou utilizar-se dos serviços do menor até seus 21 anos.

5 Utilizo a expressão aparentemente porque se sabe que, embora o temor inicial dos ex-proprietários de cativos negros pela debandada de suas escravarias, tal não se deu e, não muito tempo após a abolição, vários dos antigos escravizados, movidos pela necessidade de trabalhar para sobreviver, de não ter para onde ir, acabaram se tornando agregados e empregados nas mesmas fazendas onde antes atuavam.

6 Compreendia a Colônia Militar do Chopim, Colônia Militar de Chapecó, Palmas, Palmas do Sul, Nossa Senhora da Luz da Boa Vista, Campos do Erê, Mangueirinha, São Sebastião do Passo do Carneiro e União da Vitória. (ARQUIVO PÚBLICO DO PARANÁ, ano?, p. 8).

7 Adequavam-se à condição de ingênuos as crianças nascidas a partir de 28 de setembro de 1871 até 13 de maio de 1888, filhos de mães cativas.

8 Kátia de Queirós Mattoso (1988) explica tal noção não tinha a mesma conotação que o conceito atual, e se referia apenas à fase de zero até sete anos, momento em que as crianças podiam estar próximas para brincar, tinham mais tempo livre e menores responsabilidades. No que tange à criança negra, na idade de cinco a seis anos muitas delas já desempenhavam tarefas (MATTOSO, 1988, p. 39). Já para os menores não escravos, ainda que sem a condição compulsória dos cativos, passando a idade de sete anos principiava uma série de atividades preparatórias para o papel que os meninos e meninas livres viriam a desempenhar na sociedade (VAINFAS, 2008, p. 377).

9 Muito comum entre as cativas ou ex-cativas que suas famílias fossem descritas como compostas pela mãe (ela mesma) e os filhos. Quanto ao pai, costumava ser descrito como "incógnito", o que poderia significar uma relação estável com cativos ou não, mas não reconhecida pela Igreja ou ainda, um pai branco, livre, mas que, não querendo se comprometer, escondia-se no anonimato.

10 Azevedo (1995, p. 2) explica que os juízes de órfãos já eram mencionados nas Ordenações Filipinas, Livro I, título 88, “[...] deveriam ser formados em Direito e escolhidos pelo rei para cuidar dos menores e de seus bens em casos de ausência ou falta do pai". No entanto, no Brasil dos séc. XVIII e XIX, era exercido por pessoas sem formação. Afirma que, "[...] a 2 de maio de 1731, foi regulamentado no Brasil o cargo dos juízes de órfãos. A partir de então, as questões relativas a órfãos menores de idade passaram a ser de sua alçada”.

\section{Referências}

ALLANIZ, A. G. C. Ingênuos e libertos: estratégias de sobrevivência familiar em épocas de transição: 1871-1895. Campinas: CMU/UNICAMP, 1997.

\section{ARQUIVO PÚBLICO DO PARANÁ.}

Recenseamento da população do Brasil-1890: Comarca da Palmas. Cidade: Editora, ano.

AZEVEDO, G. C. Os juízes de órfãos e a institucionalização do trabalho infantil no século XIX. Revista Histórica, São Paulo, p. 1-9, 1995. Disponível em <http://www.historica. arquivoestado.sp.gov.br/materias/anteriores/ edicao27/materia01/texto01.pdf $>$. Acesso em: 12 set. 2016.

BRASIL. Lei $\mathrm{n}^{\circ} 2.040$, de 28 de setembro de 1871. Declara de condição livre os filhos de mulher escrava que nascerem desde a data desta lei, libertos os escravos da Nação e outros, e providencia sobre a criação e tratamento daquelles filhos menores e sobre a libertação annaul de escravos. Coleção de Leis do Brasil, Rio de Janeiro, 28 set. 1871. Disponível em: <http://www.planalto.gov.br/ccivil_03/Leis/LIM/ LIM2040.htm>. Acesso em: 14 ago. 2016.

DAVID, A. Tutores e tutelados: a infância desvalida em Franca (1850-1888). 1997. 00 f. Dissertação (Mestrado em História) - Programa de PósGraduação em História, Direito e Serviço Social, Universidade Estadual Paulista, São Paulo, 1997.

FRANCISCO, R. P. Autonomia e liberdade: os processos de tutelas de menores ingênuos e libertos 
- Juiz de Fora (1870-1900). Cadernos de Ciências Humanas - Especiaria, v. 10, n. 18, p. 649-676, jul./dez. 2007. Disponível em: <http://www.uesc. br/revistas/especiarias/ed18/11_raquel_francisco. pdf $>$. Acesso em: 17 dez. 2016.

MATTOSO, K. de Q. O filho da escrava (em torno da Lei do Ventre Livre). Revista Brasileira de História, São Paulo, v. 8, n. 16, p. 37-55, mar./ago. 1988.

MONSMA, K. Escravidão nas estâncias do Rio Grande do Sul: estratégias de dominação e de resistência. In: ENCONTRO ESCRAVIDÃO E LIBERDADE NO BRASIL MERIDIONAL, 5., 2011, Porto Alegre. Anais eletrônicos... Porto Alegre: UFRGS, 2011. Disponível em: <http://www. escravidaoeliberdade.com.br/site/images/Textos5/ monsma\%20karl.pdf $>$. Acesso em: 27 fev. 2016.

OLIVEIRA, I. de S. Programa de Direito Romano. 2. ed. Canoas: Editora da ULBRA, 2000.

PAPALI, M. A. C. R. Ingênuos e órfãos pobres: a utilização do trabalho infantil no final da escravidão. Estudos Ibero-Americanos, PUCRS, v. XXXIII, n. 1, p. 149-159, jun. 2007. Disponível em: <revistaseletronicas.pucrs.br/ojs/index.php/ iberoamericana/article/download/.../1758>. Acesso em: 10 set. 2016.
SILVA, N. S. da. O "batismo na instrução": projetos e práticas de instrução formal de escravos, libertos e ingênuos no Paraná Provincial. 2014. 00 f. Dissertação (Mestrado em História) - Programa de Pós-Graduação História, Universidade Federal do Paraná, Curitiba, 2014.

SIQUEIRA, A. P. P. de. Primeiras notas sobre os proprietários e suas posses em Palmas. In: ENCONTRO ESCRAVIDÃO E LIBERDADE NO BRASIL MERIDIONAL, 4., 13-15 maio 2009, Curitiba. Anais eletrônicos... Curitiba: Universidade Federal do Paraná, 2009. Disponível em: <http://www.escravidaoeliberdade.com.br/site/ images/Textos4/anapaulapruner.pdf $>$. Acesso em: 23 jul. 2014.

VAINFAS, R. (Org.). Dicionário do Brasil Imperial. Rio de Janeiro: Objetiva, 2008.

ZERO, A. H. O preço da liberdade: caminhos da infância tutelada - Rio Claro (1871-1888). 2004. 148 f. Dissertação (Mestrado em Ciências Econômicas) - Programa de Pós-Graduação em Ciências Econômicas, Universidade Estadual de Campinas, Campinas, 2004. Disponível em: <http:// www.bibliotecadigital.unicamp.br/document/?code $=\mathrm{vtl} 000329956 \& \mathrm{fd}=\mathrm{y}>$. Acesso em: 5 set. 2016 . 